\title{
Time to take another look at perceived disadvantages of robotic hepatectomy
}

\author{
Yasushi Hasegawa, Hiroyuki Nitta, Takeshi Takahara, Akira Sasaki \\ Department of Surgery, Iwate Medical University School of Medicine, Morioka City, Iwate, Japan \\ Correspondence to: Yasushi Hasegawa, MD, PhD. Department of Surgery, Iwate Medical University School of Medicine, 19-1 Uchimaru, Morioka \\ City, 020-8505 Iwate, Japan. Email: hasegawayas@yahoo.co.jp. \\ Provenance and Peer Review: This article was commissioned by the Editorial Office, Hepatobiliary Surgery and Nutrition. The article did not undergo \\ external peer review. \\ Comment on: Melstrom LG, Warner SG, Woo Y, et al. Selecting incision-dominant cases for robotic liver resection: towards outpatient hepatectomy \\ with rapid recovery. Hepatobiliary Surg Nutr 2018;7:77-84.
}

Submitted Oct 01, 2019. Accepted for publication Oct 10, 2019.

doi: 10.21037/hbsn.2019.10.14

View this article at: http://dx.doi.org/10.21037/hbsn.2019.10.14

Robotic hepatectomy remains controversial to date, despite continuous advances in the technology and more surgeons gaining experience with the method. Melstrom et al. (1) recently published an interesting article in Hepatobiliary Surgery and Nutrition, titled "Selecting incision-dominant cases for robotic liver resection: towards outpatient hepatectomy with rapid recovery." The authors evaluated 97 cases of robotically-assisted liver resection (RLR) arguing that it is difficult to reach the superior-posterior liver segments with the straight instruments used in conventional laparoscopic liver resection (LLR). The articulated instruments of the surgical robot are better suited for hepatectomies in these difficult-to-reach areas of the liver. They concluded that cases where the incision of an open approach would be large and affect recovery results in the highest likelihood of patients benefitting from a robotic approach. We think that the authors present an interesting perspective by focusing on the strong points of RLR compared to LLR.

In reports on LLR, tumors located in segments 7 or 8 were more difficult to resect compared to those in other locations as reflected in longer operative times and more intraoperative bleeding $(2,3)$. Guerra et al. (4) argued that robotics might greatly improve results and expand the applications of minimally invasive liver resection especially in segment 7 tumors because they increase the surgeon's dexterity, provide a three-dimensional view, and integrate ultrasonography. However, concerns remain not only regarding the port placements and performance of the
Pringle maneuver but also when the need for a conversion to open surgery requires an immediate response from the surgeon (5). These disadvantages are likely to be overcome with experience and the further development of RLR in the near future.

An international consensus statement on robotic hepatectomy was published in 2019 (6). Its seven recommendations were generated by the grading of recommendations, assessment, development and evaluations method and focused on the safety, feasibility, indications, techniques, and cost-effectiveness of the procedure. However, the current evidence level for RLR was graded as low to very low because no randomized-control trials have been performed so far, and the numbers of patients undergoing RLR are still limited. In other words, RLR is a developing technique. Randomized-controlled trials and large-scale case-control studies are required to evaluate the outcomes of RLR and validate the recommendations.

Guan et al. (7) performed a meta-analysis of thirteen articles involving 938 patients that compared RLR with LLR in 2019. RLR had longer operative times and higher intraoperative blood loss and cost than LLR. However, in the subgroup analysis of surgeries performed after 2010, a lower conversion rate was observed in RLR while other clinical outcomes were comparable between RLR and LLR. Another systematic review assessed the reasons for conversion to open surgery during RLR in more than 1,000 patients (8). The conversion rate was $4.8 \%$. Among 
the reasons were bleeding in ten patients, oncological considerations in seven patients, and difficult location or technical problems in four patients each. These results were almost predictable, but the evidence level was again low. More cases are required to understand the outcomes and challenges of RLR.

Chong et al. (9) compared RLR with LLR based on a difficulty score and found that the perioperative outcomes were similar in cases of low and intermediate difficulty. Moreover, the difficulty scoring system was significantly correlated with surgical outcomes in patients who underwent RLR. Consequently, surgeons should start with low-difficulty cases before proceeding to cases presenting high levels of difficulty. The learning curve of RLR was also described by Chen et al. (10), and they suggested that surgeons' confidence when performing major hepatectomy results from not only the assistance of robotic instruments but also their experience with LLR. Sound knowledge of liver anatomy, substantial experience with both liver surgery and laparoscopy, and adequate training in robotic surgery are required before attempting RLR (11). These findings are similar to what has been described for the learning process of conventional LLR (12).

Robotic platforms cause startup costs that include the equipment, time dedicated to the surgeon's learning of the procedures, and training of support staff to implement the technology efficiently. Several articles mention the high cost of RLR. However, Cortolillo et al. (13) analyzed a nationwide database in the United States and reported that RLR was associated with a favorable cost when comparing its outcomes with LLR and open liver resection. RLR had a lower mortality rate during initial admission and readmission, shorter length of stay, and lower total cost of the initial admission compared to both other procedures.

RLR is a developing method that is continuously improving. As with any new method, and similar to the initial phase of conventional LLR, this results in a patient selection bias. Just as LLR has its advantages such as less bleeding due to the pneumoperitoneum and magnification, RLR theoretically possesses its distinct advantages, such as providing a clear, stable, three-dimensional, and magnified field of vision, flexibility, dexterity, seven-degree freedom instruments, an ergonomic position for the surgeon, and a tremor filter. Specifically, we believe that the higher flexibility and seven-degree freedom instruments might overcome the major disadvantages of conventional LLR. Melstrom et al. (1) emphasized the characteristics features of RLR and proposed that it surmounts the weak points of conventional LLR.

We think that the possibilities of robotic surgery are still underutilized. More efforts should be made to explore its strong points and potential clinical superiority.

\section{Acknowledgments}

We would like to thank Editage (www.editage.com) for English language editing.

Funding: None.

\section{Footnote}

Conflicts of Interest: All authors have completed the ICMJE uniform disclosure form (available at https://hbsn. amegroups.com/article/view/10.21037/hbsn.2019.10.14/coif). The authors have no conflicts of interest to declare.

Ethical Statement: The authors are accountable for all aspects of the work in ensuring that questions related to the accuracy or integrity of any part of the work are appropriately investigated and resolved.

Open Access Statement: This is an Open Access article distributed in accordance with the Creative Commons Attribution-NonCommercial-NoDerivs 4.0 International License (CC BY-NC-ND 4.0), which permits the noncommercial replication and distribution of the article with the strict proviso that no changes or edits are made and the original work is properly cited (including links to both the formal publication through the relevant DOI and the license). See: https://creativecommons.org/licenses/by-nc$\mathrm{nd} / 4.0 \%$.

\section{References}

1. Melstrom LG, Warner SG, Woo Y, et al. Selecting incision-dominant cases for robotic liver resection: towards outpatient hepatectomy with rapid recovery. Hepatobiliary Surg Nutr 2018;7:77-84.

2. Ban $\mathrm{D}$, Tanabe $\mathrm{M}$, Ito $\mathrm{H}$, et al. A novel difficulty scoring system for laparoscopic liver resection. J Hepatobiliary Pancreat Sci 2014;21:745-53.

3. Hasegawa Y, Wakabayashi G, Nitta H, et al. A novel model for prediction of pure laparoscopic liver resection surgical difficulty. Surg Endosc 2017;31:5356-63.

4. Guerra F, Bonapasta SA, Annecchiarico M, et al. Liver Malignancies in Segment VII: The Role of Robot-assisted 
Surgery. Ann Surg 2017;265:E80.

5. Fung AKY, Lee KF. Robotic resection for posterosuperior liver lesions: is it really superior to laparoscopic resection? Hepatobiliary Surg Nutr 2019;8:264-6.

6. Liu R, Wakabayashi G, Kim HJ, et al. International consensus statement on robotic hepatectomy surgery in 2018. World J Gastroenterol 2019;25:1432-44.

7. Guan R, Chen Y, Yang K, et al. Clinical efficacy of robotassisted versus laparoscopic liver resection: a meta analysis. Asian J Surg 2019;42:19-31.

8. Gheza F, Esposito S, Gruessner S, et al. Reasons for open conversion in robotic liver surgery: A systematic review with pooled analysis of more than 1000 patients. Int J Med Robot 2019;15:e1976.

9. Chong CCN, Lok HT, Fung AKY, et al. Robotic versus

Cite this article as: Hasegawa Y, Nitta H, Takahara T, Sasaki A. Time to take another look at perceived disadvantages of robotic hepatectomy. HepatoBiliary Surg Nutr 2020;9(2):208-210. doi: 10.21037/hbsn.2019.10.14 laparoscopic hepatectomy: application of the difficulty scoring system. Surg Endosc 2019. [Epub ahead of print].

10. Chen PD, Wu CY, Hu RH, et al. Robotic major hepatectomy: Is there a learning curve? Surgery 2017;161:642-9.

11. Lai ECH, Tang CN. Training robotic hepatectomy: the Hong Kong experience and perspective. Hepatobiliary Surg Nutr 2017;6:222-9.

12. Hasegawa $Y$, Nitta $H$, Takahara $T$, et al. Safely extending the indications of laparoscopic liver resection: When should we start laparoscopic major hepatectomy? Surg Endosc 2017;31:309-16.

13. Cortolillo N, Patel C, Parreco J, et al. Nationwide outcomes and costs of laparoscopic and robotic vs. open hepatectomy. J Robot Surg 2019;13:557-65. 